\title{
The psychedelic religion of mystical consciousness
}

\author{
William A. Richards \\ Sacred Knowledge: Psychedelics and Religious Experiences \\ Columbia University Press, New York, 2016, 244 pp. \\ Hardback ISBN: 978-0-231-17406-0
}

With an extreme range of terms for psychedelic drugs from "schizotoxic" to "entheogenic" - "psychedelic," nonetheless remains the most salient one. These substances manifest or disclose aspects of the mind of those who take them as well as the mind of those who study them. Proponents for the innumerable terms for these drugs are all able to adduce supportive evidence. Necessarily, this evidence is a subjective experience, but in the research world, rating scales provide statistical support for one's beliefs about the nature of the drug effect: "psychotomimetic" (GouzoulisMayfrank et al., 1998) or "mystical-type" (Griffiths, Richards, McCann, \& Jesse, 2006).

The mysticomimetic model - which emphasizes the similarities between psychedelic drug effects and those described in the "mystical" literature - is increasingly popular in the renewal of clinical psychedelic studies. The primary site for the practice and promulgation of the mysticomimetic protocol is Johns Hopkins University, where Roland Griffiths is the principal investigator and William Richards the lead psychotherapist. The publication of Richards' Sacred Knowledge and his subsequent interviews and lectures shed light on the model from which devolves this successful protocol.

This model originated with Richards and colleagues including Walter Pahnke and Stanislav Grof - at the Spring Grove research center outside of Baltimore in the 1960s. These researchers demonstrated promising initial results with lysergic acid diethylamide (LSD) and N,Ndipropyltryptamine in treating addictions and end-of-life despair. However, this research ended in the early 1970s for reasons additional to the onerous regulatory burdens that the Controlled Substances Act placed on human studies at that time.

I learned of these additional factors from Eberhardt Uhlenhuth in the mid-1980s, several years before, I began the DMT and psilocybin projects at the University of New Mexico. Dr. Uhlenhuth, formerly acting Chair of Psychiatry at the University of Chicago and former President of the American College of Neuropsychopharmacology, had recently joined our department after many years at Hopkins. I shared my interest with him in clinical psychedelic drug research, as well as admiration for the Spring Grove studies, prompting him to relate his experience as a National Institute of Mental Health (NIMH) site visitor at Spring Grove, whose grant was up for renewal.

Dr. Uhlenhuth told me that the Spring Grove results were indeed promising. What resulted in the grant's non-renewal, however, was the team's having "gotten religion." By this he meant that they believed their results established the existence of a new paradigm, one that resided outside the world of clinical research and the scientific method. Rather than seeing their data as indicating effects of psychedelics on secular psychological and neurobiological functions, Richards and colleagues saw their data as proving certain religious truths. For example, they took at face value patients' reports of "the indestructibility of consciousness." That is, such reports established the fact that consciousness was indeed indestructible, rather than stimulating further research into the nature and underlying mechanisms of that experience. For the Spring Grove group, it now was a matter of extending the application of "the indestructibility of consciousness" into as many arenas - clinical and others - as possible.

Similarly, promising early results are now emerging from Johns Hopkins' and other groups' use of Richards' Spring Grove protocol. As a result, he has resurrected the new paradigm, the psychedelic religion that NIMH previously had refuted. He describes the model in what appears to be the foundational text of that religion in Sacred Knowledge. It is a troubling manifesto: anti-scientific yet points to science for its validation, prioritizes feeling over reason and certainty over truth, is intolerant of and demeans competing models. As Richards' model is essentially religious - proclaiming a new universal religion - he reserves his most damning remarks for Judaism, the particularistic religion that has perennially received the enmity of similarly universal creeds. While Richards' religious model ought not to call into question the efficacy of the protocol devolving from it, its underlying theological premises must be acknowledged and debated.

A useful notion in understanding how psychedelics can be so many different things to so many different people is that of meaning enhancement, a type of psychological placebo effect (Hartogsohn, 2018). That is, certain preexisting more-or-less conscious beliefs now become certain. They attain what Freedman (1968) referred to as "portentousness."

In Richards' case, his foundational revelation - the turning point of portentousness - occurred at the age of 23 on psilocybin in a German research study supervised by Hanscarl Leuner. Richards, a Christian with an interest in the ministry, also held to notions of universal religious experience as explicated by William James and operationalized by Walter Stace and Ralph Hood. James,

This is an open-access article distributed under the terms of the Creative Commons Attribution-NonCommercial 4.0 International License, which permits unrestricted use, distribution, and reproduction in any medium for non-commercial purposes, provided the original author and source are credited, a link to the CC License is provided, and changes - if any - are indicated. 
in turn, was directly influenced by the Vedantist Swami Vivekananda whose calls for a universal religion - that is, his universal religion - at the First World Parliament of Religions in Chicago in the 1890s met with great acclaim. Not surprisingly, Richards' initial drug experience confirmed these beliefs - that an undifferentiated, wordless, and ecstatic, time- and space-transcending experience was indeed accessible. His beliefs regarding the existence and salutary properties of such an experience then led him and his future Spring Grove colleagues to develop a protocol to maximize the likelihood of such experiences occurring in the clinical setting.

The teachings of the new psychedelic religion of mystical consciousness that Richards imparts are a mélange of New Age, Vedanta, and Christianity. He summarizes them in his catechismal 13 Insights in Sacred Knowledge's epilogue. Many of these are identical to ideas the truth of which became certain to him in 1963. For example, "reality is," and one's "favorite words and concepts" are irrelevant in understanding it; "Beauty may be in and through the eye of the Beholder, but it can be Absolute and incredibly magnificent" (note the portentous capitalization), and so on. None of these are scientifically or objectively verifiable. Rather, they are matters of belief, certainty, and conviction; that is, faith.

How then, does this experience heal and foster growth? It does so miraculously, as Christian theologian Paul Tillich's quote from Sacred Knowledge's front matter indicates: "There is no revelation without salvation." In this, he follows the Christian tradition that what one believes, and not what one does, is salvific. And whenever a course of action must be taken, Richards simply recommends "connecting with the source of mystical consciousness."

Richards makes short order - by caricaturing and then dismissing those caricatures - of two competing models. These are science - especially psychopharmacology - and academic religious studies. He mocks the former by denigrating what he sees as their misguided interpretation of religious experience as "squirts of hormones" and "mere electrical impulses." One must wonder how this misguided caricature comes about; that is, what is Richards' scientific background and training. Here, it is worth noting that his doctorate is in counseling, not clinical psychology, and is from the School of Education at Catholic University, not from a psychology department in a secular institution.

Regarding the world of academic religious studies, his rebuke is more personal. That is, neither his Yale Divinity School graduate student classmates nor teachers evinced any interest in his youthful ideas regarding a psychedelic drug-induced universal religious experience. Thus, he approvingly refers to "sociologists"" assessment of religious academics as suffering from "cultural lag." One day, they will see that he was right.

Richards' model is religious and its foundational experience is mystical-unitive, non-particularistic. Its hallmarks, as measured by Stace- and Hood-inspired rating scales, are unity, transcendence of time and space, intuitive knowledge, sacredness, deeply felt positive mood, and ineffability. As opposed to this type, there also exists an interactiverelational one, a notion I develop in depth in "DMT and the Soul of Prophecy" (Strassman, 2014). Here, one maintains a sense of self, content is highly verbal, the emotional impact is often distressing, and time and space continue much as they normally do.

Richards calls interactive-relational religious experience "visionary." Its paradigm is the prophetic experience as articulated in the Hebrew Bible (Old Testament), where there is not one mention of mystical-unitive states. While "potentially useful," Richards refers to visionary experiences as "apexes of foothills," whereas his own mysticalunitive attainment resides on the "peaks of mountaintops," which the lower foothills surround.

In an astonishingly dense two pages, 172-173, Richards takes on the Jewish prophetic tradition: its foundational experience, prophecy; spokespeople - Moses, the prophets, and the rabbis; and scriptures. For example, Moses was only "allegedly" or "said to have been" inspired; or perhaps he was simply sleep-deprived, hungry, "munching on mushrooms," or generally stressed out. On the other hand, Plato, whom Richards admires, reached his insights through "a unique biochemistry." The theophany of the other major prophet Richards refers to - Isaiah - is notable for its "fear and guilt." Finally, Richards informs us that prophetic scripture "never fell out of the skies and hit prophets on the head." The potential loss of such scripture, albeit "tragic," would soon enough be replaced by others. Luckily, we have Sacred Knowledge and the 13 Insights, outdoing Moses by three.

Compare Richards' appraisal of Judaism with that of Christianity. Without qualifications like "alleged," "said to have," and so on, we learn about the vision of "St. Paul" of "the risen Christ" on the "Road to Damascus" (note the portentous capitalization of "Road"). That Christ for Richards is "fully divine and fully human, capable of experiencing both the agony of the crucifixion and the joy of resurrection." In fact, for Richards, the frequent sightings of "the Christ archetype" in both research and indigenous settings possess eschatological significance. It is clear that he is speaking as a member of the Christian faithful.

Richards makes a point of referring to the Jewishness of the one patient whom he reports as failing to reach the mystical goal of his therapy (pp. 104-106). Or if she had, she "hid it from him," a puzzling interpretation, considering how the entire course of treatment focused on its attainment. In addition, it is more likely one would feign success rather than failure in such a transference-laden session. Or maybe she "lacked the vocabulary" to describe it. Of course, Richards never mentions lack of vocabulary when extolling the "ineffable" nature of the mystical experience. In other words, why doesn't Richards extol, not impugn, her putative lack of vocabulary?

Both Richards and Griffiths aver to Richards" "religious scholar" qualifications. However, there is little evidence for even a basic understanding of Hebrew Scripture, prophecy, and the prophetic tradition. For example, he misquotes the Shema, the most well-known verse in the Hebrew Bible (Deuteronomy 6:4) on page 58. Elsewhere he suggests that David visited Solomon's temple in Jerusalem, despite its not being built until years after his death (p. 91). On the same page, he also wonders if a particular psalm was composed in "Palestine," a name the Romans gave to conquered Judea centuries after the Psalms' composition. He then offers a 
balm to those Jews whom he might have offended by referring to the "shared" "Judeo-Christian" tradition of "washing in the blood of the lamb" (p. 172) - neither an image nor a ritual ever encountered in Judaism. Notwithstanding his "respect" for the tradition, and his "Jewish, born in Israel" girlfriend, his maligning of Judaism is unique in its scope. It again points to the religious nature of his model.

Richards' anti-Judaic polemic may devolve from his devaluation of its foundational interactive-relational prophetic experience relative to the one he ranks more highly. It also may relate to his early drug experiences supervised by the psychiatrist Leuner, who had served in Hitler's armed services during World War II (https://en.wikipedia.org/ wiki/Hanscarl_Leuner; accessed on: January 30, 2018). Jung, as well, to whom Richards attributes great importance, believed that "Jewish psychology" precluded their analyzability (Dohe, 2016). According to Jung, Jews lacked the Aryan's rootedness in the earth and therefore lacked the Aryan's connection with the earth's spiritual power. Instead, Jews' relationship was with their God, the Hebrew Bible, and the tradition's legal codes. In addition, Jung believed that because Jews originally came from the desert, a landscape lacking creativity and vitality, so did the Jewish psychology. Mostly, though, it seems to devolve from his Christianity, a religion whose founder and beliefs he views much more positively. For the apostle Paul and the Christianity which followed in his wake, traditional Jews are seen to be people of the flesh and not the spirit, lawbound, and parochial. These are the usual arguments raised by universal religions against Judaism.

Richards' rush to demean things Judaic also affects his ability to appreciate the significance of the interactiverelational effects of DMT. By ranking lower the "visionary" state of prophecy, he ranks lower the effects and utility of the DMT state, which is simply his opinion, and for which there is no evidence. He also misses an opportunity to argue for the universality of religious experience by minimizing the significance of endogenous DMT. Because the DMT effect does not comport with his notion of universal religious experience, he dismisses its significance altogether. The most he can say about it is that we are all in possession of a Schedule I drug.

One of the questions I brought to bear on my DMT studies was that of the drug's "inherent spirituality," a notion to which Richards subscribes and that he states early on in Sacred Knowledge. Not as convinced, I wondered if in a neutral setting with nearly no expectations other than describing the DMT state, would DMT produce an enlightened mystical experience? Our results indicated that DMT in and of itself was only "psychedelic," not "mysticomimetic." Volunteers' experiences were consistent with their preexisting personalities, goals, hopes, fears, and current relationships. It was clear that a program of preparatory indoctrination, manualization of session supervision, and extensive integrative work was necessary to direct the "meaning-enhancing" effects of the drug toward spiritual goals.

Richards points to the success of the Spring Grove protocol in its current iteration at Hopkins as proof of his model's truth, as he and his former colleagues did in the 1960s. In lectures and interviews, he emphasizes his membership in the Hopkins team. He taught them his protocol, is a co-author on all their major publications, and teaches others the Hopkins method. Both Griffiths and Richards qualify Richards' relationship with Hopkins as an "independent contractor." However, this is a distinction that most would find meaningless. Without Richards, there would be no Hopkins projects; without Hopkins, Richards' model would have continued lying fallow. And while Griffiths has asked me not to "conflate" Richards' views with those of every past or present member of the Hopkins' team - a list of which he provided me - he has done little or nothing to articulate how his views differ from Richards'.

There are clinical/practical implications of Richards' model, not simply theological objections. For example, was the failure of his Jewish patient to reach mystical-unitive consciousness because she was Jewish - somehow constitutionally incapable - or because of how Richards treated her - verbally or non-verbally - because she was Jewish? Richards also provides a music playlist that many other sites have adopted. This list is heavily oriented toward Western European (the work of Wagner, a vicious anti-Semite, is prominent), as well as Christian and East Indian pieces. There is no Jewish or Israeli music, a striking omission as nearly every current study is taking place in urban centers with large Jewish populations.

There is no comparable reading list in Sacred Knowledge. However, in my role as an editor for a recent Frontiers in Pharmacology research topic, I noted the books available to patients in a manuscript describing the results of an endof-life psilocybin study: Christianity, Buddhism, mystical traditions, meditation, mindfulness, and death and dying. When queried, the authors replied that these books were provided by staff, not stipulated in the protocol. Nevertheless, this is another stark omission, and indicates an unconscious accession to this model's anti-Semitic ethos. Wouldn't Job, Psalms, Proverbs, the Song of Songs stimulate powerful and therapeutically useful associations in Jewish (and non-Jewish) patients?

More generally, Richards' ideas are faith- rather than data-based. For example, what if death is not like a psychedelic vision, as Richards suggests, "mystical consciousness awaiting us all"? Nor is it a "transition" or a Buddha-like "waking up"? What if there is, despite Richards' claim, no reincarnation? And what if, after all, consciousness is destructible? A dying person may expect something entirely different from what actually occurs as they are dying or once dead. Is this fair to the dying? And the Hopkins imprimatur which Richards displays so prominently lends his religious beliefs an air of scientific legitimacy they do not possess.

It is in this light that one should retain a healthy skepticism for the "religious leaders" studies now occurring at New York University and Hopkins. Griffiths has advised me that preliminary results indicate that experiences are "more similar than different." Translated, this means that scores on the Mystical Experience Questionnaire are more similar than different across adherents of different faiths. It is inevitable that researchers will use these data to support their notion of a "universal, core, primary mystical experience" underlying all particular faiths. Psilocybin effects will thus establish that Judaism is like any other religion. 
However, these data are more likely to be explained by two more salient reasons. First is selection bias. Traditional Jews who love and revere the one God of Israel and the Jewish law, believe that Jews have an ancestral right to the "promised land," and pride themselves in their "chosenness," in addition to finding Richards' views unpalatable, would never volunteer. And for those who do, there's no reason to believe that their response to psilocybin combined with the RichardsHopkins protocol would differ from anyone else's.

The title of Sacred Knowledge's penultimate chapter is "Entering into a New Paradigm." This is the paradigm that was already once soundly rejected by the scientific research community. It is advisable to reject it this time as well, despite the success of the psychotherapy protocol devolving from it. There are many other secular and testable ways to understand this method's utility without inventing a new religion.

How to remedy some of these issues? Clinical research with psychedelics must remain within the mainstream. Overreaching into theology and religion, most obviously exemplified by the loose use of "mystical" to describe particular drug effects, is certain to generate backlash from bona fide religions. No religious tradition is going to simply accept the proposition that their foundational spiritual experience is "mystical consciousness" that most people can reach with several hours of psychotherapy and a psychedelic drug.

There are clearly phenomenological similarities between certain religious experiences in long-time, dedicated practitioners of spiritual traditions and those brought on by psychedelics. But to equate the two is a categorical error. In "DMT and the Soul of Prophecy," I point to similarly impressive phenomenological overlap between the DMT and prophetic states. However, the DMT and prophetic experiences fundamentally differ in their origin, mechanisms, meanings, messages, and impact for the individual and his/her community. "Peak," "peak psychedelic," or "psychedelic" were the terms the Spring Grove and other groups used previously. There is no reason not to use them now they are secular, psychological, and remain within our present paradigm.

It is important to refrain from glorifying the psychedelic drug state. Simply look at how Charles Manson used LSD's meaning-enhancing effects in those similarly predisposed to particular goals and aspirations (Bugliosi, 1994). Just as important, Richards seeks to render their adverse effects innocuous. Contrary to the universal practice of excluding prepsychotic or formerly psychotic individuals from psychedelic drug administration studies, he casually suggests that psychedelics may actually help such people. Psychedelics may hasten their entry into treatment (through precipitating a psychotic break?) or prevent psychosis through uncovering relevant psychic conflicts (p. 185). The use by the Hopkins' group of the term "challenging experiences" to describe the entire temporal and qualitative range of adverse psychedelic drug effects (Barrett, Bradstreet, Leoustakos, Johnson, \& Griffiths, 2016) is consistent with this downplaying of negative reactions. It is new paradigm-speak and situates the field outside of mainstream clinical biomedicine and psychotherapy research and practice. Severe chronic psychosis after psychedelic drug ingestion is no more a "challenging experience" than is a heart attack resulting from methamphetamine use.

Dr. Daniel X. Freedman was one of the most important mentors and advocates for my DMT research. During one of our early brainstorming sessions, he advised me to remain alert to difficulties with staff who might tarnish the reputability of the research. In this light, it is of note how Richards offers an inordinately sympathetic view of Tim Leary, who nearly single-handedly derailed legitimate clinical research for a generation. Leary's alarming mantra: "turn on, tune in, and drop out" evidenced the inability of psychedelic researchers to rein in their own messianic pretensions. Richards, whose lectures bear titles like "Revelation Now," is not calling for secular, scientific research, but a call to arms, a religious revolution. This is something that the field, now just recovering from decades of neglect, cannot afford.

\section{REFERENCES}

Barrett, F. S., Bradstreet, M. P., Leoutsakos, J.-M. S., Johnson, M. W., \& Griffiths, R. R. (2016). The Challenging Experience Questionnaire: Characterization of challenging experiences with psilocybin mushrooms. Journal of Psychopharmacology, 30(12), 1279-1295. doi:10.1177/0269881116678781

Bugliosi, V. (1994). Helter Skelter. The true story of the Manson murders (2nd ed.). New York, NY: W. W. Norton \& Company, Inc.

Dohe, C. B. (2016). Jung's wandering archetype: Race and religion in analytical psychology. London, UK: Routledge.

Freedman, D. X. (1968). On the use and abuse of LSD. Archives of General Psychiatry, 18(3), 330-347. doi:10.1001/archpsyc. 1968.01740030074008

Gouzoulis-Mayfrank, E., Habermeyer, E., Hermle, L., Steinmeyer, A. M., Kunert, H. J., \& Sass, H. (1998). Hallucinogenic drug induced states resemble acute endogenous psychoses: Results of an empirical study. European Psychiatry, 13(8), 399-406. doi:10.1016/S0924-9338(99)80686-5

Griffiths, R. R., Richards, W. A., McCann, U., \& Jesse, R. (2006). Psilocybin can occasion mystical-type experiences having substantial and sustained personal meaning and spiritual significance. Psychopharmacology, 187(3), 268-283. doi:10.1007/ s00213-006-0457-5

Hartogsohn, I. (2018). The meaning enhancing properties of psychedelics and their mediator role in psychedelic therapy, spirituality, and creativity. Frontiers in Neuroscience, 12(129). doi:10.3389/fnins.2018.00129

Strassman, R. (2014). DMT and the soul of prophecy. Rochester, VT: Park Street Press.

Rick J. Strassman, MD

Department of Psychiatry, University of New Mexico School of Medicine Albuquerque, NM 87131, USA E-mail: rjstrassman@gmail.com 